\title{
Lateral hypothalamic kindling induces manic-like behavior in rats: a novel animal model
}

\author{
Osama A Abulseoud ${ }^{1 *}$, Ulas M Camsari ${ }^{1}$, Christina L Ruby ${ }^{2}$, Khalid Mohamed ${ }^{2}$, Noha M Abdel Gawad ${ }^{1}$, Aimen Kasasbeh ${ }^{3}$, \\ Mehmet Y Yüksel ${ }^{2}$ and Doo-Sup Choi ${ }^{1,2}$
}

\begin{abstract}
The lateral hypothalamus integrates critical physiological functions such as the sleep-wake cycle, energy expenditure, and sexual behaviors. These functions are severely dysregulated during mania. In this study, we successfully induced manic-like behavioral phenotypes in adult, male Wistar rats through bilateral lateral hypothalamic area kindling (LHK). To test the validity of the model, we studied the effect of standard antimanic medications lithium $(47.5 \mathrm{mg} / \mathrm{kg})$ or valproic acid $(200 \mathrm{mg} / \mathrm{kg}$ ) twice/day for 15 days in attenuating manic-like behaviors in the LHK rat. Compared with pre-kindling behaviors, LHK rats displayed significantly increased sexual self-stimulation $(P=0.034)$, excessive rearing $(P=0.0005)$, feeding $(P=0.013)$, and grooming $(P=0.007)$ during the kindling interval. LHK rats also drank more alcohol during the mania-induction days compared with baseline ethanol consumption levels $(P=0.01)$. Moreover, LHK rat exhibited increased total locomotor activity $(P=0.02)$ with reduced rest interval $(P<0.001)$ during the mania induction and post-mania days compared with baseline activity levels and rest intervals. Chronic administration of lithium or valproic acid significantly attenuated manic-like behaviors in the LHK rat model. Given the behavioral phenotype and the response to standard antimanic medications, the LHK rats may provide a model for studying manic psychopathology in humans.
\end{abstract}

Keywords: Lateral hypothalamus; Kindling; Manic; Circadian genes; Lithium; Valproic acid

\section{Background}

Bipolar disorder is a common, recurrent medical illness (Merikangas et al. 2007) characterized by at least one manic episode (type I) or alternating episodes of mania (or hypomania in type II) and depression (American Psychiatric Association 2000; Goodwin and Jamison 2007; Judd et al. 2002). In the United States, up to $1 \%$ of the general population will suffer from bipolar disorder type I (Merikangas et al. 2007) during their lifetime, leading to significant disability (Murray and Lopez 1997) and high rates of completed suicide (Inskip et al. 1998; Tondo et al. 2003). The acute manic episode, the hallmark of bipolar disorder, is a medical emergency that frequently requires hospitalization (Hirschfeld et al. 2006). Current pharmacological interventions can be divided into three groups: lithium, anticonvulsants, and atypical antipsychotics. The efficacy of these agents as monotherapies in the treatment

\footnotetext{
* Correspondence: Abulseoud.Osama@mayo.edu

'Department of Psychiatry and Psychology, Mayo Clinic, 200 First Street SW, Rochester, MN 55905, USA

Full list of author information is available at the end of the article
}

of acute mania in randomized controlled trials approximates 50\% response and only 25\% remission (McElroy and Keck 2000; Perlis et al. 2006). The suboptimal efficacy of antimanic medications stems, at least in part, from the fact that the underlying neural mechanisms triggering and maintaining a manic episode remain largely unknown.

Animal models simulating the manic illness are essential to understanding the complex pathophysiology of this disorder. There are currently two major categories of animal models that exhibit manic-like behaviors. In the first, the manic-like behavior is induced by behavioral stress (e.g., sleep deprivation) or chemical treatment (e.g., methamphetamine). In the second, specific gene or pathway alterations such as circadian locomotor output cycles kaput (CLOCK); or extracellular signal regulated protein kinases 1 (ERK1) known to be implicated in bipolar disorder are introduced into animals (Chen et al. 2010). Despite being highly valuable in studying this complex disorder, current animal models have several limitations. For example, in the models with genetic alterations, although the proteins encoded by the genes of human and rodents 
are highly homologous, the regulation of gene transcription by transcription factors or epigenetics, or the regulation of gene translation by microRNAs, can vary extensively between humans and rodents. Furthermore, the gene-behavior relationships of some behaviors may be conserved only to a certain extent between the human and animal genomes (Chen et al. 2010). Similarly, amphetamine treatment in rodents is a well-accepted mania model, while in humans, it could induce a syndrome virtually indistinguishable from paranoid schizophrenia. These observations highlight the significant need to identify new valid mania models that exhibit more phenotypic features of the illness and link certain aspects of manic-like behaviors to the underlying neural networks. In this study, we propose a novel animal model through kindling of the lateral hypothalamic area in rats.

The hypothalamus coordinates various neural systems that mediate different functional responses (Bouret and Simerly 2004), integrates the motivational aspects of behavior with visceral-motor responses, regulates energy homeostasis (Williams et al. 2001), initiates sexual behavior (Beauregard et al. 2001; Ferretti et al. 2005; Hamann et al. 2004; Redoute et al. 2000), and synchronizes the rhythms of all biological processes with environmental changes to achieve the optimal adaptive response (Mendlewicz and Linkowski 1987). The lateral hypothalamus in particular has been implicated in the processing of sensory information and the expression of behaviors associated with hunger and thirst, aggression, and reproduction (Bernardis and Bellinger, 1993). The lateral hypothalamus is involved in mediating general arousal and sensory sensitization associated with motivational behavior (de Lecea et al. 2012). Several lines of evidence suggest the involvement of the hypothalamus in the pathophysiology of mania. Structural brain imaging studies suggest a dilation of the third ventricle in the region where hypothalamic nuclei are located adjacent to its walls, indirectly implicating reduced hypothalamic volume (Bhadoria et al. 2003; Cousins et al. 2010; Pearlson et al. 1997; Strakowski et al. 1993). Furthermore, two postmortem studies (Bielau et al. 2005; Brisch et al. 2011) showed significant reduction in the volume of the hypothalamic region in patients with bipolar disorder type I compared to those with major depression and healthy controls.

Moreover, preclinical studies in rats (Kruk 1991), pigs (Ettrup et al. 2012), and monkeys (Lacan et al. 2008) have shown that high-frequency stimulation of the hypothalamus engages functional circuits involved in different behaviors reminiscent of mania such as hypersexuality, aggression, increased locomotor activity, and disturbed sleep-wake cycle. In the female Gottingen pig, transient aggressive territorial behavior followed by increased locomotor activity and no sleep for the first night was reported following bilateral stimulation of the lateral hypothalamus (Ettrup et al. 2012). In the vervet monkey, bilateral high-frequency stimulation of the ventromedial hypothalamus elicited a transient period of agitated and sexual behavior (Lacan et al. 2008). Based on the aforementioned evidence, we hypothesized that the lateral hypothalamus was the logical target to induce manic-like behaviors. However, there remains the question of the stimulation pattern optimal for induction of manic behavior.

Kindling is a well-established concept referring to the development of a full seizure as a result of the delivery of repeated subthreshold stimuli. Amygdala kindling has been proposed by Post and Weiss (1989) as a model of epilepsy to explain the efficacy of the anticonvulsant carbamazepine in treatment of mania in patients with bipolar disorder. However, the symptomatology induced by amygdala kindling was distinct from any caused by mania (Post and Weiss 1989). In this study, we investigated a novel animal model of mania induced by delivering brief stimulation pulses to the lateral hypothalamus.

\section{Methods \\ Animals}

The experiments were done on adult male Wistar rats (age 12 to 16 weeks, weight 250 to $300 \mathrm{gm}$ at beginning of experiment) obtained from Charles River Laboratories International, Inc. (Wilmington, MA, USA). Rats were housed in individual cages on a 12-h light/dark cycle (lights on at 6 a.m.), free supply of food (ad libitum), and tap water. All experimental procedures were approved by the Mayo Clinic Institutional Animal Care and Use Committee.

\section{Experimental groups}

Phenotype experiments had four groups ( $n=8$ each) designed to compare the effect of kindling vs. sham at the lateral hypothalamus and two other control brain regions: the nucleus accumbens (NAC) shell and the infralimbic cortex (ILC). The NAC shell was chosen for its role in reward circuitry (Russo and Nestler 2013) which is known to be intimately involved in manic behaviors. The IL cortex is a subregion of the prefrontal cortex (PFC). In the rat, the PFC consists of medial prefrontal cortex (mPFC) and orbitofrontal cortex (OFC). The mPFC is functionally linked to the limbic system (Vertes 2006) and anatomically is subdivided into infralimbic (IL), prelimbic $(\mathrm{PL})$, and dorsal anterior cingulate (dAC) (Czeh et al. 2008). The PL cortex, homologues to dorsolateral prefrontal cortex in humans (Laroche et al. 2000) projects to insular cortex, thalamus, amygdala, hippocampus and ventral tegmental area (Vertes 2006). The PL cortex is thought to be directly involved in limbic and cognitive function (Marquis et al. 2007). The IL cortex in rats, on the other hand, is analogues to the subgenual Brodmann area 25 in humans (Drevets et al. 1997; Ongur et al. 2003). 
Deep brain stimulation of area 25 is associated with successful treatment of refractory depression (Mayberg et al. 1999, 2005).

Predictive validity experiments had three groups $(n=$ 12 each). All received lateral hypothalamic area kindling (LHK) and were assigned to lithium, VPA, or saline treatment to test the efficacy of standard antimanic medications in attenuating manic-like behavior. Animals were allowed a 1-week habituation interval before surgery and mania induction procedures followed by 7 days of postmania before euthanasia and brain collection were performed. A diagrammatic illustration of the study design is depicted in Figure 1A.

\section{Surgical implantation of stimulating electrodes}

Anesthetized animals (isoflurane inhalation, 3.0\% during induction and $1 \%$ to $1.5 \%$ during maintenance) were secured in the stereotaxic apparatus (David Kopf Instruments, Tujunga, CA, USA) and the skull leveled between bregma and lambda. Bipolar stimulating electrodes (\#MS303 twisted stainless steel, outer diameter $125 \mu \mathrm{m}$, Plastics One, Inc., Roanoke, VA, USA) were implanted bilaterally into the lateral hypothalamic area (A/P, $-2.28 ; \mathrm{M} / \mathrm{L}, \pm 2.7$; $\mathrm{D} / \mathrm{V},-8.5 \mathrm{~mm}$ from skull surface) and in the nucleus accumbens shell in another group of animals $(\mathrm{A} / \mathrm{P},+1.2$; $\mathrm{M} / \mathrm{L}, \pm 2.7 ; \mathrm{D} / \mathrm{V},-8.5 \mathrm{~mm}$ from skull surface) and in the ILC in a third group $(\mathrm{A} / \mathrm{P},+3.24 ; \mathrm{M} / \mathrm{L}, \pm 2.4 ; \mathrm{D} / \mathrm{V},-5.1 \mathrm{~mm}$

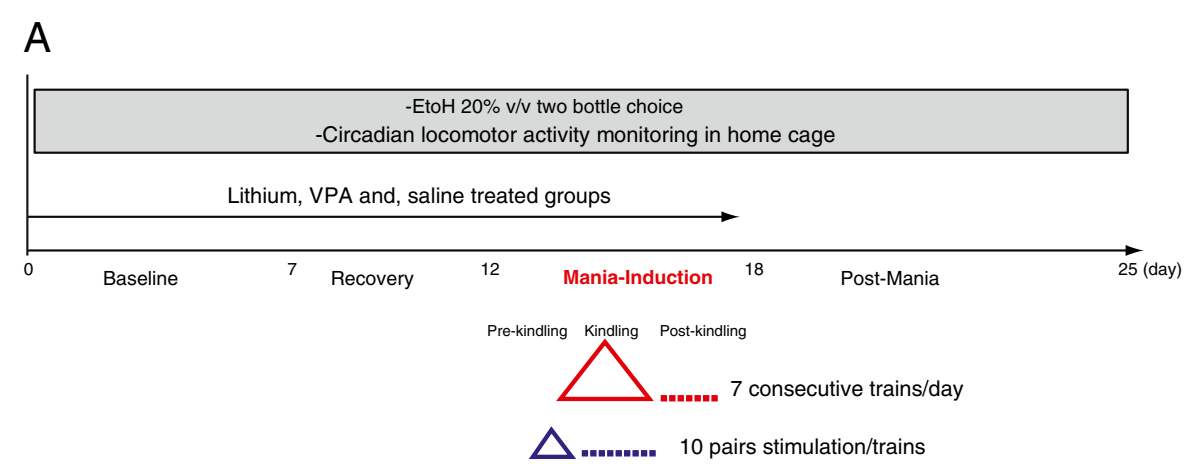

B Bregma -2.08

Bregma -2.28 Bregma -2.6

Bregma -2.85
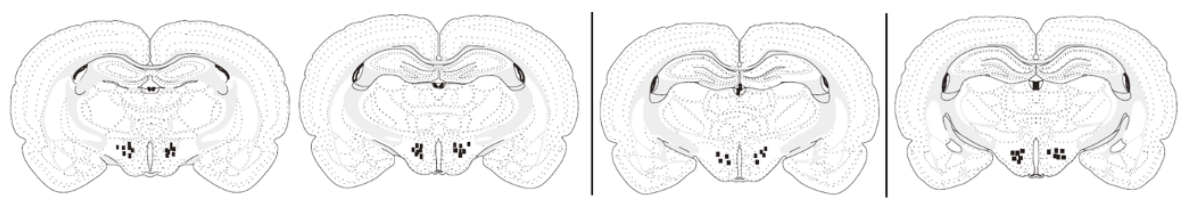

C
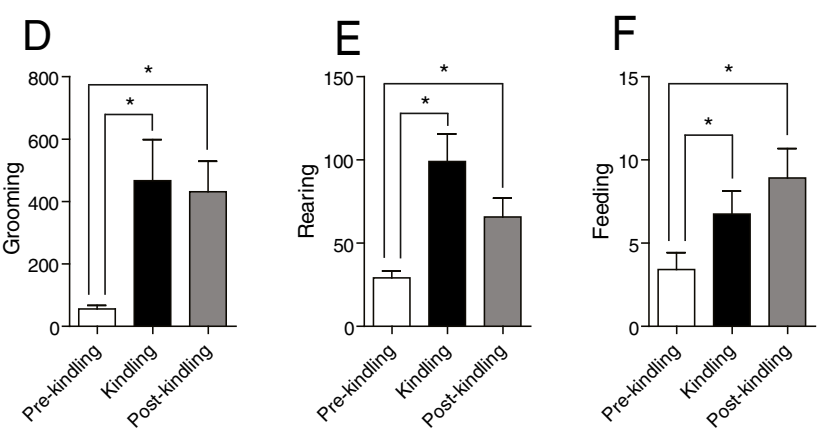

Figure 1 Study design, electrode location, and kindling-induced manic-like behaviors. Study design shown in (A) included the baseline phase for 7 days, followed by surgical implantation of stimulating electrode and recovery for 5 days before mania induction took place for 5 days. Each day, the animal was allowed an initial pre-kindling habituation period for 30 min followed by kindling phase consisting of seven consecutive trains of escalating volts ( 1 through $7 \mathrm{~V}$ ) with 2-min rest interval between trains. Each train consisted of 10 pairs of stimulation (10 s) alternating with rest (30 s). The animal remained in the monitored cage for 30 min during the post-kindling period before it was returned back to home cage for 7 days (post-mania) before euthanasia and brain collection was performed. Locomotor activity counts and voluntary ethanol consumption were monitored continuously throughout the study period. Animals were assigned to lithium, valproate (VPA), or saline for 15 days. (B) An illustration of stimulating electrode tip locations plotted within the dorso-medial part of the LHA regions. AP coordinates were between - 1.7 and - 2.8 from bregma according to Paxinos Atlas. Manic-like behaviors were elicited in LHK rats. Significant increase in the frequency of sexual behavior (C), duration of grooming (D), the frequency of rearing (E), and feeding behaviors (F) were evident during the kindling process and persisted during the post-kindling interval by two-way ANOVA; ${ }^{*} P<0.05$ by post hoc test; $n=10$ to 12 per group. Data is expressed as mean \pm SEM. 
from skull surface). All electrodes were implanted with a $20^{\circ}$ angle to allow enough room to attach the stimulating cords in both sides. Electrodes were secured to the skull using dental cement and three screws. Animals were closely observed over 5 days post-surgery. Animals with any neurological signs of brain damage were excluded from the study.

\section{Mania-induction procedure}

All procedures took place in the early light phase between 6 a.m. and 8 a.m. during mania induction days. The animal was placed individually into a clear Plexiglas cage $\left(12 " \times 12^{\prime \prime} \times 30\right.$ ", with ordinary bedding and food pellets on the floor) for $30 \mathrm{~min}$ at the beginning of the experiment to habituate to the new environment. This interval was called the pre-kindling interval and was followed by $60 \mathrm{~min}$ of kindling using the following stimulation parameters: bipolar configuration, $180 \mathrm{~Hz} / \mathrm{s}$ frequency, $500 \mu$ s pulse width, and 10-s pulse durations followed by $30 \mathrm{~s}$ of rest. Seven trains were applied, each consisting of 10 pairings of $10-\mathrm{s}$ duration stimulation pulses alternating with $30 \mathrm{~s}$ of rest, and $2 \mathrm{~min}$ of rest were allowed between trains. Stimulation amplitude was started at $1 \mathrm{~V}$ and was increased by $1 \mathrm{~V}$ for each stimulation train. These stimulation parameters were chosen empirically to simulate the clinical DBS parameters used in the voltage-dependent mania case report (Chopra et al. 2011). Following all seven kindling trains, the animal was kept in the observation chamber for 30 more minutes as post-kindling interval. Subsequently, the stimulating cord was disconnected and the animal was returned back to the home cage. The exact same procedure was repeated for five consecutive days. The number of mania-induction days was also chosen arbitrary to replicate a manic episode in humans that usually lasts several days.

\section{Monitoring and quantifying behaviors during the process of mania induction}

Continuous video recording of behaviors was performed over the 2-h mania-induction session. Recorded video files were transferred and stored in two separate external hard drives. Each animal recording was reviewed independently and behaviors were coded separately by two trained blinded raters (UC and MY), and target behaviors were reviewed by the principal investigator of the study (OA). The four primary behaviors were coded: (1) sexual behavior, the number of any oral contact with the genital area (erected or flaccid penis or testicles) or immediate perigenital area (Additional file 1: Video S1); (2) rearing behavior, the number of episodes of standing on the two hind limbs for more than $5 \mathrm{~s}$ duration (Additional file 2: Video S2); (3) grooming behavior, the total time (in 5-second increments) of repeated mouthing of any body part except the genital and perigenital areas or repeated movement of the fore or hind paws over the snout, face, head, trunk, or tail (Additional file 3: Video S3); and (4) feeding behavior, the number of times where the animal is observed holding and chewing food pellets. Chewing without food or chewing bedding was not considered feeding behavior (Additional file 4: Video S4). We developed this novel method of continuous monitoring, identifying, and quantifying clear individual manic-like behaviors reminiscent of clinical mania rating scales.

\section{4-h sleep-wake cycle and locomotor activity monitoring} in home cage during baseline, mania-induction, and post-mania days

Circadian locomotor activity counts in home cage were recorded using an infrared motion detector interfaced with a computerized data acquisition system (ClockLab, ActiMetrics, Wilmette, IL, USA) and later analyzed using MATLAB (The MathWorks, Inc., Natick, MA, USA). Total locomotor activity counts (bout analysis) and total activity time for light and dark phases were measured separately for each day of the experiment during baseline, mania-induction days, and post-mania days. The nonactivity time was calculated by subtracting total activity time (minutes) from $720 \mathrm{~min}$ (12-h light/dark phase). This outcome measure was used as a surrogate marker for rest or sleep.

\section{Voluntary ethanol consumption via two-bottle choice paradigm}

Animals in both the phenotype experiments and predictive validity experiments were offered $20 \%(v / v)$ ethanol vs. tap water in a two-bottle choice paradigm throughout the experiment. Water, ethanol, and food consumption were measured by weighing the animal, the two bottles, and the food pellets in the feeding tray daily. To avoid the confounding of side preference, we switched the bottle side every time fluid measurements were taken.

To examine the potential confounding effect of ethanol on the induced behaviors, we compared manic-like behaviors between voluntary ethanol-drinking and water-only drinking rats ( $n=8$ each).

\section{Lithium and valproate sodium treatment}

Lithium (47.5 mg/kg; Sigma, St. Louis, MO, USA) or VPA (200 mg/kg; Sigma, St. Louis, MO, USA) and saline (1 ml) IP twice/day were administered for 15 consecutive days (10 days before and 5 days during mania-induction). No lithium, VPA, or saline were administered during the post-mania days. Lithium carbonate was dissolved in distilled water $30 \mathrm{mg} / \mathrm{mL}$, and VPA was dissolved in $0.9 \%$ $50 \mathrm{mg} / \mathrm{mL}$ saline according to manufacturer guidelines. 
The chronic treatment and the doses of VPA and lithium were based on previous studies (Castro et al. 2009; Feier et al. 2013; Frey et al. 2006a, b) demonstrating the safety and yielding therapeutic lithium blood levels in the range of 0.8 to $1.1 \mathrm{mEq} / \mathrm{L}$, closely resembling therapeutic levels used to treat humans with bipolar disorder (Nolen and Weisler 2013).

\section{Euthanasia and brain histology for verification of electrode tip location}

Animals were lightly anesthetized in $\mathrm{CO}_{2}$ chamber and euthanized by rapid decapitation around the same time (2000 hours for all animals). The brain was carefully collected and fixed in paraformaldehyde solution for $24 \mathrm{~h}$ followed by $30 \%$ sucrose solution for 1 week then covered with optimal cooling temperature (OCT) compound for cryostat sectioning (Ted Pella Inc., Redding, CA, USA) and stored at $-80^{\circ} \mathrm{C}$ until histology was performed. Brains were sectioned on a cryostat $(50 \mu \mathrm{m})$ and stained with hematoxylin and eosin. Verification of electrode tip location was done according to the atlas of Paxinos and Watson (1998).

\section{Statistical analysis}

The behavioral outcomes for each day during the three observation intervals (i.e., pre-kindling, kindling, and post-kindling) were first analyzed with repeated measures analyses of variance (ANOVAs). For simplicity, the sum of all events of an individual parameter that took place during all days in the observation interval was then re-analyzed. To test for differences in individual behavioral manifestations, two-way ANOVAs were used with factors of time (baseline vs. mania induction vs. post-mania) and groups (LHK-Sham vs. LHK-stim vs. NAC, vs. ILC) or factors of time (baseline vs. mania induction vs. postmania) and treatment (LHK/saline vs. LHK/VPA vs. LHK/ lithium). When a significant interaction was found, a post hoc testing was performed to determine pairwise differences. One-way ANOVAs were used to examine differences in individual behaviors during kindling between groups (LHK vs. NAC vs. ILC) and to compare behaviors during each interval (pre-kindling, kindling and postkindling) within the LHK group. All data were presented as means \pm SEM. Results were considered significant when $P<0.05$.

\section{Results}

A total of 84 animals were used in this study. Data from nine subjects were excluded for animals that died $(n=3)$, that pulled the electrode prior to or during kindling $(n=2)$, or in cases where electrodes were found outside the target brain region $(n=4)$ as confirmed by histological examination. To assess for potential electrode-associated brain tissue damage, we have examined the motor function of each rat post-implantation for any neurological deficit. Furthermore, we examined brain tissue histology for any evidence of hemorrhage or infarction. A diagram for the projected electrode tip location in the LHK group is shown in Figure 1B.

\section{LHK induces manic-like behavior in naïve rats}

Sexual behavior was observed exclusively in animals that underwent LHK (Additional file 5: Figure S1A). Within the LHK group, the frequency of sexual behavior showed a significant increase during kindling and post-kindling compared with pre-kindling levels: one-way ANOVA $F_{2,33}=3.364, P=0.0468$, post hoc $t$ test pre-kindling vs. kindling $(t=2.416, d f=11, P=0.034)$, and pre-kindling vs. post-kindling $(t=3.493, d f=11, P=0.005$, Figure $1 C)$. A significant increase in the total time spent in grooming behavior was evident in the LHK compared with the kindled NAC or kindled ILC groups during kindling $\left(F_{2,21}=5.821\right.$, $P=0.009$, Additional file 5: Figure S1B). Also in the LHK group, the duration of grooming behavior showed a significant increase during kindling and post-kindling compared with pre-kindling levels: one-way ANOVA $F_{2,33}=5.76, P=0.007$, post hoc $t$ test pre-kindling vs. kindling $(t=3.268, d f=11, P=0.007)$, pre-kindling vs. post-kindling $(t=4.029, d f=11, P=0.002$, Figure $1 \mathrm{D})$. A significant increase in the frequency of rearing behavior was observed in the LHK compared with the kindled NAC and ILC groups during kindling $\left(F_{2,21}=13.78, P=0.0001\right.$, Additional file 5: Figure S1C). In the LHK group, the frequency of rearing behavior showed a significant increase during kindling and post-kindling compared with prekindling levels: one-way ANOVA $F_{2,33}=8.799, P=0.0009$, post hoc $t$ test pre-kindling vs. kindling $(t=4.88, d f=11$, $P=0.0005)$, pre-kindling vs. post-kindling $(t=3.391, d f=$ $11, P=0.006$, Figure 1E). A significant increase in feeding behavior was seen in the LHK group compared with the kindled NAC and ILC groups during kindling $\left(F_{2,23}=\right.$ 12.67, $P=0.0002$, Additional file 5: Figure S1D). In the LHK group, the frequency of feeding behavior showed a significant increase during kindling and post-kindling compared with pre-kindling levels: one-way ANOVA $F_{2,33}=3.838, P=0.031$, post hoc $t$ test pre-kindling vs. kindling $(t=2.932, d f=11, P=0.013)$, pre-kindling vs. post-kindling $(t=2.956, d f=11, P=0.013$, Figure $1 \mathrm{~F})$.

To examine the potential confounding effect of concomitant ethanol consumption on elicited manic-like behaviors or the possibility that differences in behaviors could have resulted from differential ethanol intake between the groups, we compared manic-like behaviors between two LHK groups, water only and ethanol (20\% $v / v$ versus water) drinking groups $(n=8$ each). We did not observe any significant differences in induced manic-like behaviors between the two groups (Additional file 6: Figure S2). 


\section{LHK-induced manic-like behaviors are attenuated by standard antimanic medications VPA and lithium}

Lithium, but not VPA, significantly attenuated the frequency of sexual behavior $\left(F_{2,31}=4.189, P=0.024\right.$, Figure $\left.2 \mathrm{~A}\right)$ and the duration of grooming behavior $\left(F_{2,34}=4.02, P=0.027\right.$, Figure 2B). Both lithium and VPA reduced the frequency of rearing behavior $\left(F_{2,34}=18.3, P<0.0001\right.$, Figure $\left.2 \mathrm{C}\right)$, but neither lithium nor VPA had an effect on the frequency of feeding behavior $\left(F_{2,31}=2.978, P=0.065\right.$, Figure 2D).

LHK is associated with reward-seeking behavior in the form of significant increase in voluntary ethanol consumption that is not attenuated by lithium or VPA treatment

Two-way ANOVA with time (baseline, mania-induction, and post-mania) and group (LHT sham, LHK, NAC, ILC) factors showed significant effect for time $\left(F_{2,46}=11.39\right.$, $P<0.0001)$, and group $\left(F_{2,46}=8.64, P=0.0007\right)$ and an interaction between the two factors $\left(F_{4,46}=3.22, P=0.026\right)$. Subsequent post hoc testing revealed a significant increase

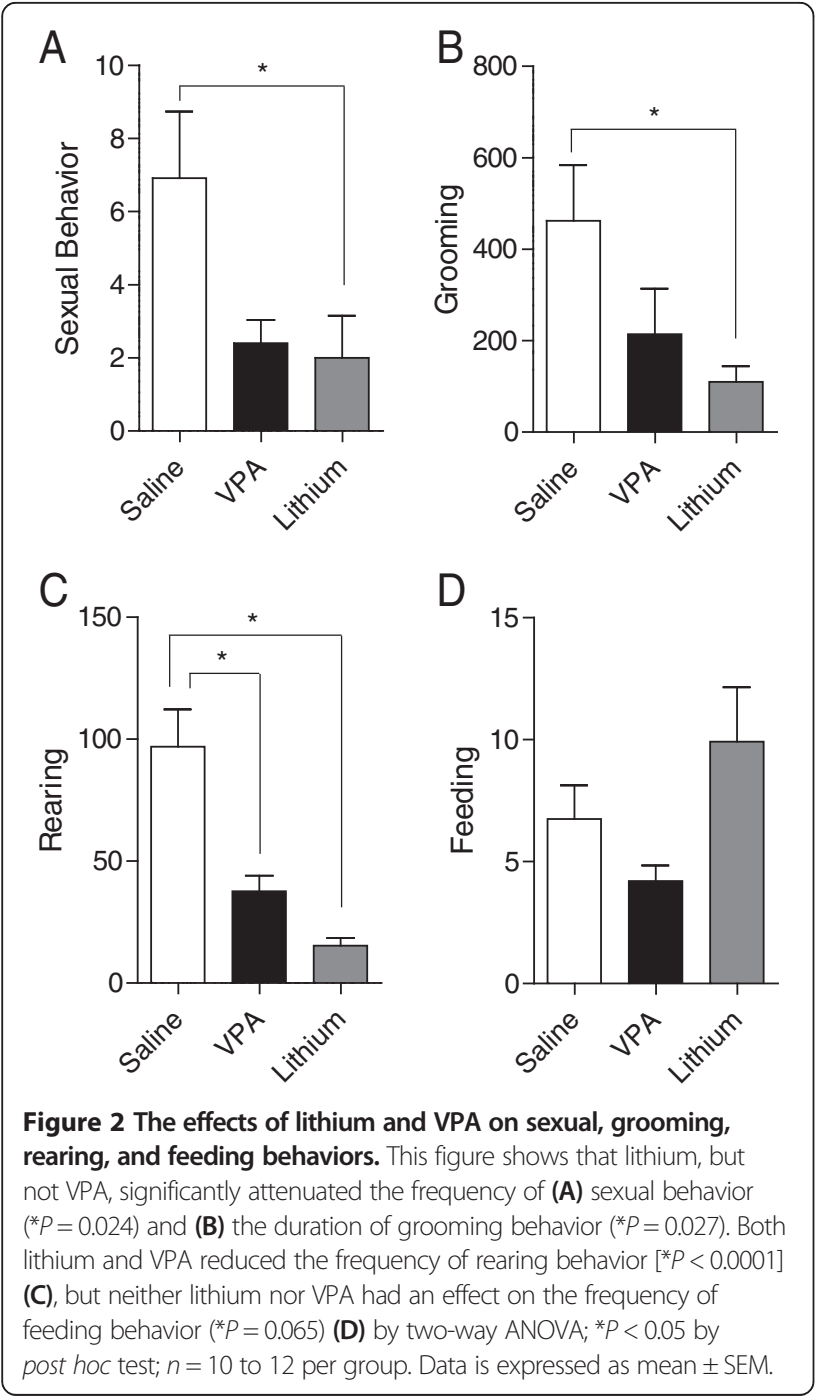

in ethanol consumption during mania-induction compared with the baseline interval in the LHK $(t=4.707, P<0.01)$ and in the NAC group $(t=3.071, P<0.05)$ but not in the $\operatorname{ILC}$ group $(t=2.79, P>0.05)$.

The significant increase in ethanol consumption remained during the post-kindling interval only in the LHK group, baseline vs. post-mania LHK $t=2.66, P<0.05$; NAC $t=0.44$, $P>0.05$; and ILC $t=0.536, P>0.05$, Figure 3A. Neither lithium nor VPA treatment had a significant effect on ethanol consumption during mania induction by two-way ANOVA, $\left(F_{4,58}=1.86, P=0.12\right.$, Figure 3B $)$.

Of note, neither lithium nor VPA had a significant effect on weight gain, (Additional file 7: Figure S3A) or food consumption (Additional file 7: Figure S3B). However, lithiumtreated rats consumed significantly more water (Additional file 7: Figure S3C) compared to saline or VPA-treated.

LHK is associated with significant increase in total activity counts and reduced rest intervals during both light and dark phases

A significant increase in the total activity counts during the light phase was evident between groups. An interaction between time (baseline, mania-induction, and post-mania) and group (LHK-sham, LHK, NAC, and ILC; $F_{6,32}=3.68$, $P<0.006)$ and subsequent post hoc testing revealed a significant increase in activity counts during mania-induction days compared with the baseline interval in the LHK $(t=7.52, P<0.001)$, and NAC $(t=3.907, P<0.01)$, but not in the LHT-sham $(t=2.46, P>0.05)$, or ILC groups $(t=2.64, P>0.05$, Figure 4A).

Examining the total activity counts during the dark phase where the animals are normally active using twoway ANOVA shows also significant difference between groups. An interaction between time and group $\left(F_{6,32}=\right.$ 2.97, $P=0.02$ ) and subsequent post hoc testing revealed a significant increase in activity counts during maniainduction compared with the baseline interval in the LHK $(t=4.73, P<0.001)$, NAC $(t=2.77, P<0.05)$, and ILC $(t=2.66, P<0.05)$ but not in the LHT-sham $(t=1.17$, $P>0.05$, Figure 4B).

Total rest interval during light phase shows a significant difference between groups. An interaction between time and group $\left(F_{6,32}=2.97, P=0.009\right)$ and subsequent post hoc testing revealed a significant decrease in total duration of rest during mania-induction compared with the baseline interval in all groups, the LHK $(t=6.764, P<0.001)$, NAC $(t=5.626, P<0.001)$, ILC $(t=3.323, P<0.01)$, and in the LHT-sham $(t=3.173, P<0.05$, Figure $4 \mathrm{C})$.

Total rest interval during dark phase shows a significant difference between groups. An interaction between time and group $\left(F_{6,32}=2.97, P=0.0005\right)$ and subsequent post hoc testing revealed no significant decrease in total duration of rest during mania-induction compared with the baseline interval in the LHK $(t=1.04, P>0.05)$, NAC $(t=0.585$, 

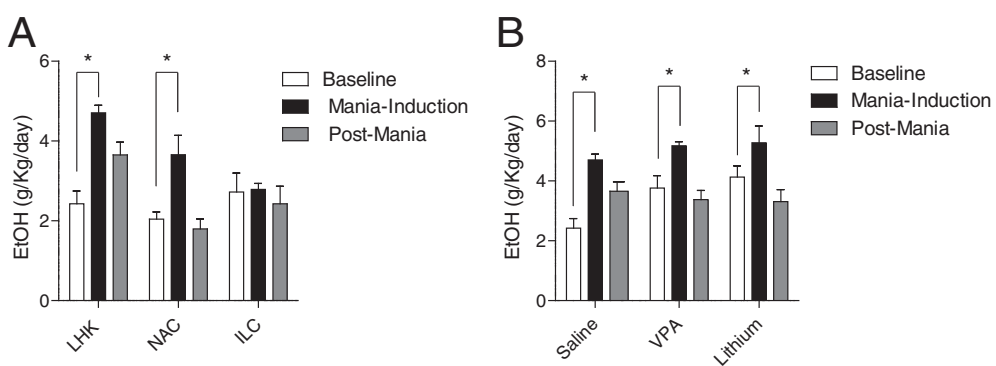

Figure 3 Effect of Kindling on ethanol consumption. Depicts the increased ethanol consumption in kindled LH, NAC, and ILC rats during maniainduction compared to baseline intervals $\left({ }^{*} P=0.026\right)(\mathbf{A})$. The significant increase in ethanol consumption remained during the post-mania interval only in the LHK group (baseline vs. post-mania LHK $(t=2.66, P<0.05)$, NAC $(t=0.44, P>0.05)$, and ILC $(t=0.536, P>0.05)$. Neither lithium nor VPA attenuated LHK-induced increase in ethanol consumption $(P=0.12)$ (B) by two-way ANOVA; ${ }^{*} P<0.05$ by post hoc test; $n=10$ to 12 per group. Data is expressed as mean \pm SEM.

$P>0.05)$, or LHT-sham $(t=1.33, P>0.05)$ and a significant increase in the ILC $(t=2.78, P<0.05$, Figure 4D).

\section{LHK-induced increased activity and reduced rest intervals} are attenuated by standard antimanic medications VPA and lithium

Two-way ANOVA shows a significant interaction between time and treatment $\left(F_{4,54}=3.69, P=0.01\right)$ and subsequent post hoc testing comparing baseline with mania-induction revealed a significant increase in total activity counts during light phase only in saline $(t=3.63, P=0.011)$, but not in VPA $(t=1.36, P>0.05)$, or lithium-treated $(t=0.495$, $P>0.05)$ groups. During the post-mania interval, salinetreated animals returned back to baseline activity, baseline vs. post-mania saline-treated group $(t=0.092, P>0.05)$, while the activity level decreased significantly in VPA ( $t=2.33, P=0.038)$, and lithium-treated $(t=4.55, P=0.019)$ animals (Figure $5 \mathrm{~A}$ ).
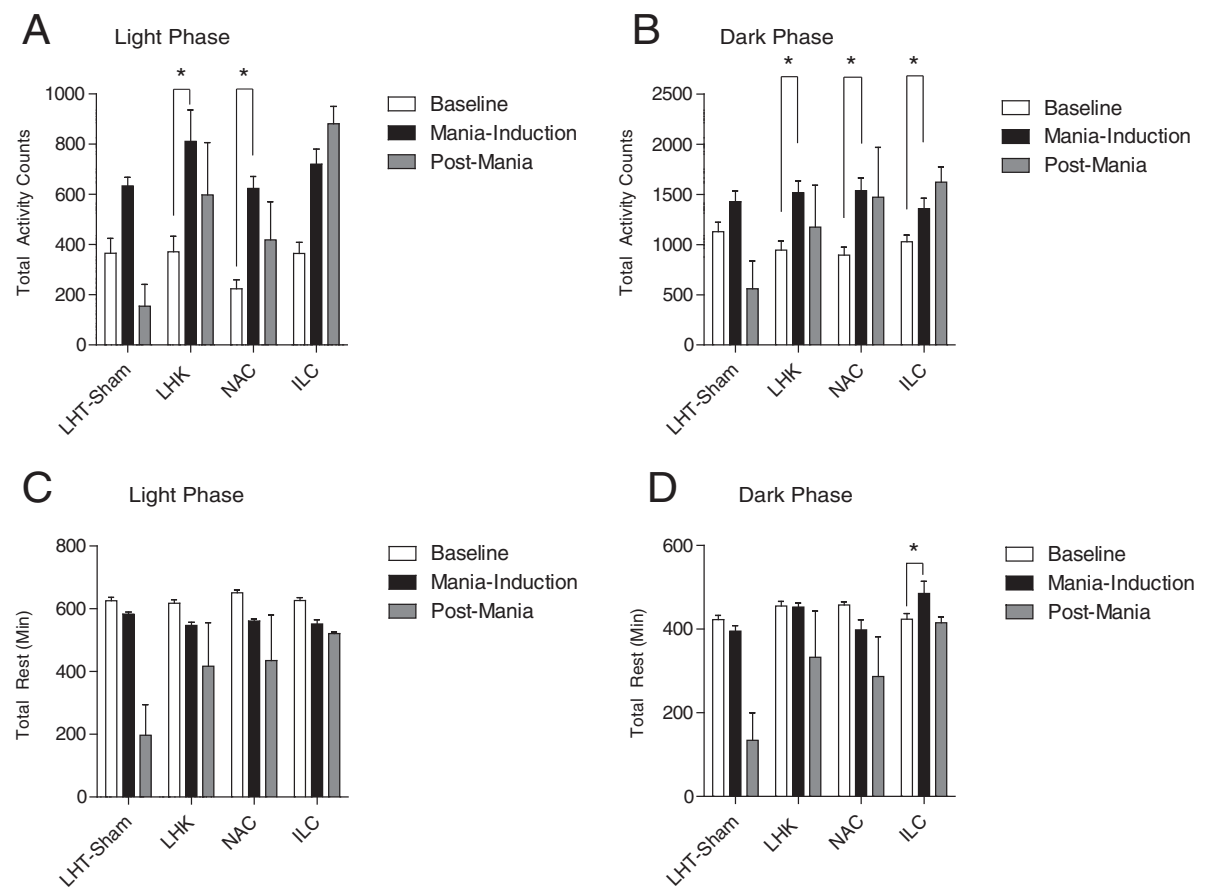

Figure 4 The impact of mania induction on total locomotor activity and rest intervals during light and dark phases. A significant increase in the total activity counts during the light phase $(\mathbf{A})$ during mania induction compared with the baseline interval. Interaction $(P<0.006)$ in the LHK (* $P<0.001)$, and NAC ( $\left.{ }^{*} P<0.01\right)$, but not in the LHT-sham $(P>0.05)$, or ILC groups $(P>0.05)$. Similarly, increased activity during the dark phase (B) was evident. Interaction $(P=0.02)$ in the LHK $(* P<0.001)$, NAC $(* P<0.05)$, and ILC $\left({ }^{*} P<0.05\right)$, but not in the LHT-sham $(P>0.05)$. Total rest interval during light phase (C) shows a significant decrease with interaction $(P=0.009)$ during mania induction compared with the baseline interval in all groups, the $L H K(* P<0.001)$, NAC ( $\left.{ }^{*} P<0.001\right)$, ILC $(* P<0.01)$, and in the LHT-sham $\left.{ }^{*} P<0.05\right)$. Total rest interval during dark phase (D) shows no significant decrease in total duration of rest during mania induction compared with the baseline interval in the LHK $(P>0.05)$, NAC $(P>0.05)$, or LHT-sham $(P>0.05)$ but and a significant increase in the ILC $(P<0.05)$ with an interaction $(P=0.0005)$ by two-way ANOVA; ${ }^{*} P<0.05$ by post hoc test; $n=8$ to 12 per group. Data is expressed as mean \pm SEM. 

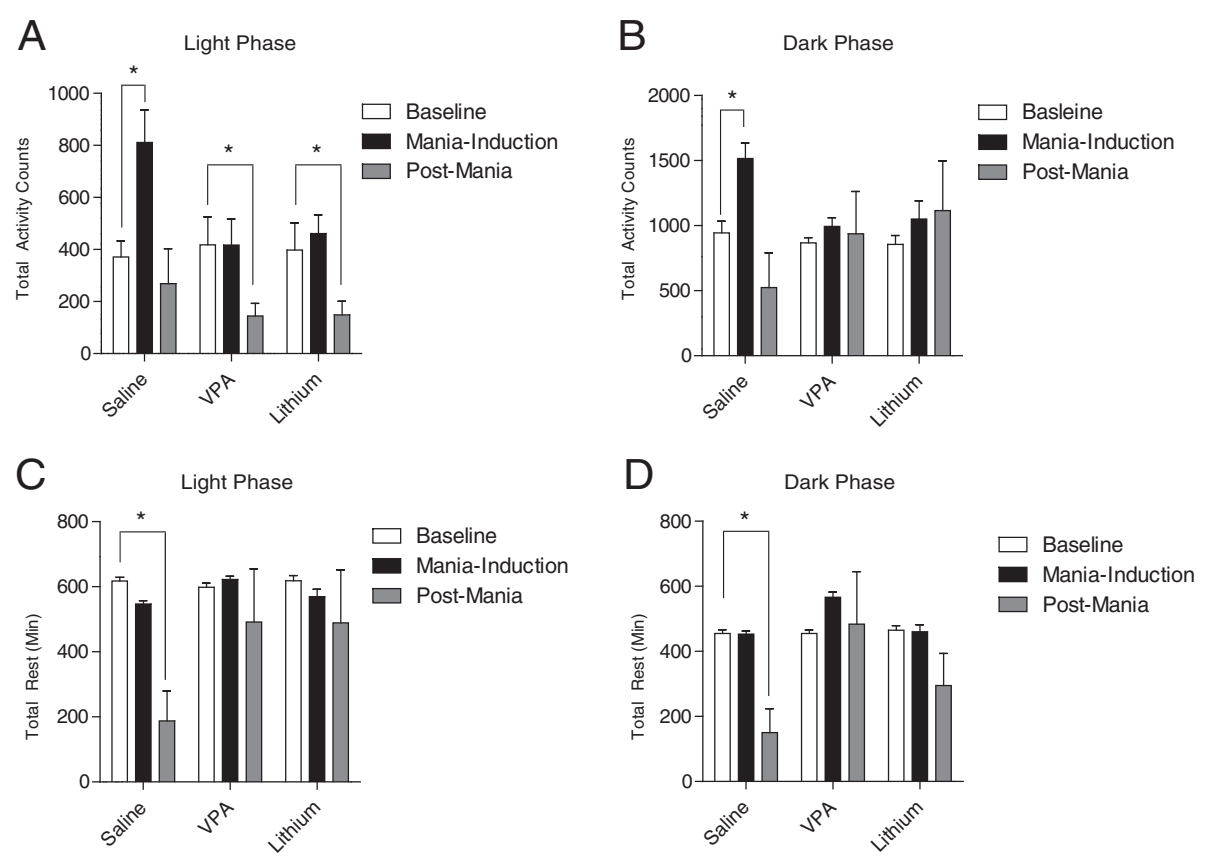

Figure 5 Impact of 15-day treatment with saline, VPA and lithium. On kindling-induced changes in total locomotor activity and rest intervals during light and dark phases. Comparing baseline with mania-induction during light phase (A) shows a significant increase in total activity counts only in saline $\left({ }^{*} P=0.011\right)$, but not in VPA $(P>0.05)$, or lithium-treated $(P>0.05)$ groups with an interaction $(* P=0.01)$, while a significant reduction in activity counts during the post-kindling interval was seen in both VPA $\left({ }^{*} P=0.038\right)$, and lithium-treated $\left({ }^{*} P=0.019\right)$ animals but not in saline-treated rats $(P>0.05)$ by two-way ANOVA; ${ }^{*}<0.05$ by post hoc test; $n=10$ to 12 per group. Data is expressed as mean \pm SEM. Contrary to saline-treated rats, VPA and lithium prevented the kindling-induced increase in activity counts during dark phase (B). Interaction $(P=0.0001)$, baseline vs. mania-induction in saline-treated group $\left({ }^{*} P<0.001\right)$, VPA-treated $(P>0.05)$, and lithium-treated $(P>0.05)$ rats by two-way ANOVA; $* P<0.05$ by post hoc test; $n=10$ to 12 per group. Data is expressed as mean \pm SEM. A significant reduction in rest interval observed during the post-kindling compared to pre-kindling days in both light (C) and dark (D) phases only in saline-treated rats ( $\left.{ }^{*} P<0.001\right)$, but not in the VPA $(P>0.05)$ or the lithium-treated $(P>0.05)$ groups. Comparing baseline vs. post-mania rest intervals during dark phase shows that saline-treated group had significant reduction $(* P<0.001)$ in rest interval that was abolished in both VPA $(P>0.05)$ and lithium-treated $(P>0.05)$ groups by two-way ANOVA; ${ }^{*} P<0.05$ by post hoc test; $n=10$ to 12 per group. Data is expressed as mean \pm SEM.

Similar attenuating effect for lithium and VPA on dark phase activity counts during mania-induction days was also evident. A significant interaction between time and treatment $\left(F_{4,54}=3.69, P=0.0001\right)$ was observed, and subsequent post hoc testing comparing baseline with maniainduction activity levels revealed a significant increase in total activity counts during dark phase only in the salinetreated group $(t=5.056, P<0.001)$, but not in VPA-treated $(t=0.45, P>0.05)$, or lithium-treated $(t=2.23, P>0.05)$ groups (Figure $5 \mathrm{~B}$ ).

As expected, the increased activity was associated with reduced rest interval observed during the post-mania days in both light $\left(F_{4,54}=3.69, P=0.0001\right)$ and dark $\left(F_{4,54}=3.69\right.$, $P=0.0001)$ phases only in saline-treated animals: light phase rest interval during baseline vs. post-mania intervals $(t=5.416, P<0.001)$, whereas no significant differences were detected in the VPA-treated $(t=2.151, P>0.05)$ or the lithium-treated $(t=0.85, P>0.05)$ groups (Figure $5 \mathrm{C})$ and also in comparing baseline vs. post-mania rest intervals during dark phase, saline-treated group show significant reduction $(t=8.918, P<0.001)$ that was abolished in both
VPA $(t=0.892, P>0.05)$ and lithium-treated $(t=0.940$, $P>0.05$ ) groups (Figure 5D).

\section{Discussion}

This study provides compelling evidence for the utility of the LHK rat as an appropriate model for multiple behavioral aspects of mania. Our findings demonstrate that the LHK rat presents a unique manic-like behavioral pattern including hypersexuality, increased grooming, rearing, and feeding behaviors. Moreover, mania induction increased voluntary ethanol consumption and locomotor activity while reducing rest for 7 days post-mania.

Sexual behavior in the form of genital self-stimulation was observed exclusively in the LHK rat during the kindling and post-kindling intervals (Figure 1C). Hypersexuality is an established criterion for diagnosing a manic episode in humans (American Psychiatric Association 2000). In this study, we adopted the frequency of genital licking as a marker for hypersexual behavior rather than the usual method of counting the frequency of male copulatory behaviors with receptive estrous females (Fiorino and Phillips 
1999; Scotti et al. 2011) to avoid the confounding element of potential stimulation of sexual behavior by the presence of a receptive female. Genital self-stimulation in male rats is well known to take place in the context of sexual behavior consistent with previous models (Roybal et al. 2007; Scotti et al. 2011); the frequency of sexual behavior in the LHK rat was reduced by lithium (Figure 2A), adding predictive validity to the model.

Interestingly, the excessive grooming behavior of nongenital areas was also elicited during the mania-induction process. Animals were observed to go into what seemed to be an 'intense excitement' with frequent rearing followed by excessive grooming and then exhibit erection and start genital licking. This pattern of development of manic-like behaviors was nearly uniform across subjects. The full pattern was occasionally seen, but the behavior did not always reach the genital self-stimulation phase. We have consistently observed the emergence of the same induced maniclike behaviors throughout all kindling days. However, induced manic-like behaviors tended to appear at progressively lower stimulation amplitudes

Important to the LHK model is the effect of specific antimanic pharmacotherapy. Lithium, but not VPA, significantly attenuated the duration of grooming behavior (Figure 2B), while the increase in rearing during LHK was attenuated by both lithium and VPA (Figure 2C). Attenuation of amphetamine-induced rearing is a well-established behavioral effect of therapeutically relevant lithium and VPA concentrations (Shaltiel et al. 2007). Neither lithium nor VPA had a significant effect on the increased frequency of feeding behavior evident in the LHK rat (Figure 2D). Interestingly, studies in humans with comorbid bipolar and eating disorders show similar poor efficacy of standard antimanic medications in treating the eating component (McElroy et al. 2005). Similarly, the reward-seeking behavior in the form of increased voluntary ethanol consumption was significantly increased during mania-induction (Figure 3A) and was not attenuated by lithium or VPA treatment (Figure 3B). Clinical studies suggest that lithium treatment does not decrease alcohol intake in patients with bipolar disorder (Lejoyeux and Ades 1993). However, in the current study, we tested the efficacy of fixed dose monotherapy with lithium or VPA. It is possible that other dosing regimens or a combination of both medications could be more effective in reducing alcohol consumption than either one alone, as suggested in some studies (Kemp et al. 2009; Salloum et al. 2005). Further experiments are needed to explore these relevant issues.

A striking feature of our model is elevated hyperactivity during both the light and dark phases. Total activity counts during mania induction and the 7 days following reached twice as high as the baseline activity levels (Figure 4A,B). Combined with the significant reduction in total duration of sleep time (Figure 4C,D) and the 'overexcitement' picture observed during the kindling process, it suggests that these animals spend almost all their time ambulating. This fits well with clinical observations of a manic episode: pacing and reduced sleep. Both lithium and VPA reduced activity (Figure 5A,B) and increased rest intervals (Figures 5C,D) concomitant with the reduction of other manic-like behaviors, adding validity to the LHK model.

The drug response profile demonstrated by lithium and VPA in just attenuating but not completely abolishing manic-like behaviors resembles the efficacy of these medications in treating humans with mania (Greil et al. 1997; Hartong et al. 2003). Combining this with the results of the first set of experiments provides face and predictive validity for the LHK rat as a model for certain domains of mania. Further investigation including dose-response studies and comparing the efficacy of individual antimanic medications to the efficacy of combined lithium and VPA together are warranted.

The LHK model differs from currently existing models of mania such as the psychomotor stimulant-induced hyperactivity model (Berggren et al. 1978; Furukawa et al. 1975; Jacobs and Silverstone 1986), dopamine transporter knockdown mice (Perry et al. 2009), CLOCK mutant mice (Roybal et al. 2007), or the Madison mice (Scotti et al. 2011) in three aspects. First, it is the first model to induce manic-like behavior through targeting a specific brain region. Second, the induction of an episode of manic-like behavior by kindling (rather than by continuous stimulation) builds on the seminal work of Post and Weiss (1989) of amygdala kindling. However, in their initial work, it was clear that amygdala-kindled rats did not exhibit manic-like behaviors. The third difference between other models and the LHK model is the ability to induce a discrete episode of maniclike behavior during kindling. This brings us closer to the episodic nature of the illness in humans and differs from the life-long manic excitement observed in some other models (Roybal et al. 2007; Scotti et al. 2011). Further studies with longer observation periods are necessary to assess whether the LHK rat cycles from the manic pole of the illness to normality or dips into depressive-like phenotype.

Our data demonstrated that the induction of manic-like behaviors is specific to kindling of the LHT and not other control regions. Several brain imaging (Bhadoria et al. 2003; Cousins et al. 2010; Pearlson et al. 1997; Strakowski et al. 1993) and postmortem studies (Bielau et al. 2005; Brisch et al. 2011) reported hypothalamic abnormalities in patients with bipolar disorder; however, our model provides compelling evidence for the central role the lateral hypothalamus plays in generating certain manifestations of mania. However, it is likely that the elicited behavioral phenotype is not stemming from the LHT solely but rather due to activation of several interfacing neural networks. Mapping cerebral blood flow changes during specific behaviors in freely moving rats using autoradiobiographic techniques (Holschneider and Maarek 2004) is necessary to explore this relevant point. 
Kindling has historically been defined in reference to a seizure activity. However, in our study, despite that electrophysiological recordings for seizure activity were not performed, we observed the manic-like behaviors at progressively lower stimulation voltage and earlier during subsequent days of stimulation compared to the first day of stimulation. In addition, we observed the same behaviors during the post-kindling interval which argues that the stimulated neurons were spontaneously firing after the end of direct stimulation which is typical of kindling. Along the same lines, it is important to note that hypothalamic deep brain stimulation has been employed clinically to treat refractory cluster headache (Franzini et al. 2007), selfaggressive behavior in a patient with mental retardation (Hernando et al. 2008), traumatic brain injury (Kuhn et al. 2008), and selected cases of intractable obesity (Whiting et al. 2013) without inducing mania or other psychiatric side effects.

In the context of the current results, it is important to note that the kindling parameters were chosen based on the clinical case report of voltage-dependent mania (Chopra et al. 2011). We only varied stimulation amplitude and fixed frequency, pulse width, and duration of stimulation train. Clinical data from subthalamic nucleus deep brain stimulation for Parkinson's disease show that motor outcome is best modulated by changes in amplitude (Kuncel and Grill 2004; (Balaz et al. 2013). Yet, it is quite possible that different behaviors will be elicited by employing other parameters.

\section{Conclusion}

In conclusion, the spectrum of induced behavioral manifestations combined with the response to antimanic medications proves the LHK rat a novel and valid model for mania.

\section{Additional files}

Additional file 1: Video S1. Sexual behavior, the number of any oral contact with the genital area (erected or flaccid penis or testicles) or immediate perigenital area.

Additional file 2: Video S2. Rearing behavior, the number of episodes of standing on the two hind limbs for more than 5-s duration.

Additional file 3: Video $\mathbf{S 3}$. Grooming behavior, the total time (in 5-s increments) of repeated mouthing of any body part except the genital and perigenital areas or repeated movement of the fore or hind paws over the snout, face, head, trunk, or tail.

Additional file 4: Video S4. Feeding behavior: the number of times where the animal is observed holding and chewing food billets; chewing without food or chewing bedding was not considered feeding behavior.

Additional file 5: Figure S1. Sexual behavior was observed exclusively in animals that underwent LHK (A), while the total time spent in grooming behavior (B) was significantly longer in the LHK compared to NAC and ILC groups during kindling ( $\left.{ }^{*} P=0.009\right)$; the frequency of rearing behavior (C) was observed significantly more in the LHK compared to NAC and ILC groups during kindling ( $\left.{ }^{*} P=0.0001\right)$, and the frequency of feeding behavior (D) was also significantly more in the LHK group compared to the NAC and
ILC groups during kindling ( ${ }^{*} P=0.0002$ ) by two-way ANOVA; $P<0.05$ by post hoc test; $n=7$ to 8 per group. Data are expressed as mean \pm SEM.

Additional file 6: Figure S2. Shows no significant differences in (A) the frequency of sexual behavior, (B) the duration of grooming behavior, (C) the frequency of rearing behavior, or (D) the frequency of feeding behavior between voluntary ethanol drinking and water-only drinking rats $(P>0.05)$ by two-way ANOVA; $n=8$ per group. Data are expressed as mean \pm SEM.

Additional file 7: Figure S3. (A) shows no significant differences in weight gain or food consumption (B) between groups, but lithium-treated rats consumed significantly more water $(\mathbf{C})$ compared to saline or VPA-treated rats $(P<0.01)$ by two-way ANOVA; $P<0.05$ by post hoc test; $n=8$ to 12 per group. Data are expressed as mean \pm SEM.

\section{Competing interests}

The authors declare that they have no conflicts of interest.

\section{Authors' contributions}

OAA conceived, designed, and conducted all experiments. OAA, DSC, and CLR designed circadian experiments. OAA, KM, and NA performed behavioral experiments. OAA and AK designed kindling parameters. UC and MY performed behavioral coding during kindling. OAA and AK performed statistical analysis. OAA prepared figures and wrote the manuscript. All authors contributed to reviewing and editing the manuscript. All authors read and approved the final manuscript.

\section{Acknowledgement}

This work is supported by a grant support from NIH/NCRR CTSA KL2 (RR024151) (OAA) and in parts by the Samuel Johnson Foundation for Genomics of Addiction Program at Mayo Clinic and by grants from the National Institutes of Health (AA018779) (DSC).

\section{Author details}

${ }^{1}$ Department of Psychiatry and Psychology, Mayo Clinic, 200 First Street SW, Rochester, MN 55905, USA. ${ }^{2}$ Department of Molecular Pharmacology and Experimental Therapeutics, Mayo Clinic, 200 First Street SW, Rochester, MN 55905, USA. ${ }^{3}$ Department of Neurosurgery, Mayo Clinic, 200 First Street SW, Rochester, MN 55905, USA.

Received: 11 February 2014 Accepted: 30 April 2014

Published online: 14 June 2014

\section{References}

American Psychiatric Association (2000) Diagnostic and Statistical Manual of Mental Disorders, 4th edition. rev: DSM-IV-R American Psychiatric Association, Washington, DC

Balaz M, Bockova M, Rektor I (2013) DBS amplitude setting can improve aspects of quality of life in patients with Parkinson's disease. J Neural Transm 120(4):643-648

Beauregard M, Levesque J, Bourgouin P (2001) Neural correlates of conscious self-regulation of emotion. J Neurosci 21(18):RC165

Berggren U, Tallstedt L, Ahlenius S, Engel J (1978) The effect of lithium on amphetamine-induced locomotor stimulation. Psychopharmacology (Berl) 59(1):41-45

Bernardis LL, Bellinger LL (1993) The lateral hypothalamic area revisited: neuroanatomy, body weight regulation, neuroendocrinology and metabolism. Neurosci Biobehav Rev 17(2):141-193

Bhadoria R, Watson D, Danson P, Ferrier IN, McAllister VI, Moore PB (2003) Enlargement of the Third Ventricle in affective disorders. Indian J Psychiatry 45(3):147-150

Bielau H, Trubner K, Krell D, Agelink MW, Bernstein HG, Stauch R, Mawrin C, Danos P, Gerhard L, Bogerts B, Baumann B (2005) Volume deficits of subcortical nuclei in mood disorders A postmortem study. Eur Arch Psychiatry Clin Neurosci 255(6):401-412

Bouret SG, Simerly RB (2004) Minireview: leptin and development of hypothalamic feeding circuits. Endocrinology 145(6):2621-2626

Brisch R, Bernstein HG, Dobrowolny H, Krell D, Stauch R, Trubner K, Steiner J, Ghabriel MN, Bielau H, Wolf R, Winter J, Kropf S, Gos T, Bogerts B (2011) A morphometric analysis of the septal nuclei in schizophrenia and affective disorders: reduced neuronal density in the lateral septal nucleus in bipolar disorder. Eur Arch Psychiatry Clin Neurosci 261(1):47-58 
Castro AA, Casagrande TS, Moretti M, Constantino L, Petronilho F, Guerra GC, Calo G, Guerrini R, Dal-Pizzol F, Quevedo J, Gavioli EC (2009) Lithium attenuates behavioral and biochemical effects of neuropeptide $\mathrm{S}$ in mice. Peptides 30(10):1914-1920

Chen G, Henter ID, Manji HK (2010) Translational research in bipolar disorder: emerging insights from genetically based models. Mol Psychiatry 15(9):883-895

Chopra A, Tye SJ, Lee KH, Matsumoto J, Klassen B, Adams AC, Stead M, Sampson S, Kall BA, Frye MA (2011) Voltage-dependent mania after subthalamic nucleus deep brain stimulation in Parkinson's disease: a case report. Biol Psychiatry 70(2):e5-e7

Cousins DA, Moore PB, Watson S, Harrison L, Ferrier IN, Young AH, Lloyd AJ (2010) Pituitary volume and third ventricle width in euthymic patients with bipolar disorder. Psychoneuroendocrinology 35(7):1074-1081

Czeh B, Perez-Cruz C, Fuchs E, Flugge G (2008) Chronic stress-induced cellular changes in the medial prefrontal cortex and their potential clinical implications: does hemisphere location matter? Behav Brain Res 190(1):1-13

de Lecea L, Carter ME, Adamantidis A (2012) Shining light on wakefulness and arousal. Biol Psychiatry 71(12):1046-1052

Drevets WC, Price JL, Simpson JR, Jr, Todd RD, Reich T, Vannier M, Raichle ME (1997) Subgenual prefrontal cortex abnormalities in mood disorders. Nature 386(6627):824-827

Ettrup KS, Sorensen JC, Rodell A, Alstrup AK, Bjarkam CR (2012) Hypothalamic deep brain stimulation influences autonomic and limbic circuitry involved in the regulation of aggression and cardiocerebrovascular control in the Gottingen minipig. Stereotact Funct Neurosurg 90(5):281-291

Feier G, Valvassori SS, Varela RB, Resende WR, Bavaresco DV, Morais MO, Scaini G, Andersen ML, Streck EL, Quevedo J (2013) Lithium and valproate modulate energy metabolism in an animal model of mania induced by methamphetamine. Pharmacol Biochem Behav 103(3):589-596

Ferretti A, Caulo M, Del Gratta C, Di Matteo R, Merla A, Montorsi F, Pizzella V, Pompa P, Rigatti P, Rossini PM, Salonia A, Tartaro A, Romani GL (2005) Dynamics of male sexual arousal: distinct components of brain activation revealed by $\mathrm{fMRI}$. Neuroimage 26(4):1086-1096

Fiorino DF, Phillips AG (1999) Facilitation of sexual behavior in male rats following d-amphetamine-induced behavioral sensitization. Psychopharmacology (Berl) 142(2):200-208

Franzini A, Marras C, Tringali G, Leone M, Ferroli P, Bussone G, Bugiani O, Broggi G (2007) Chronic high frequency stimulation of the posteromedial hypothalamus in facial pain syndromes and behaviour disorders. Acta Neurochir Suppl 97(Pt 2):399-406

Frey BN, Andreazza AC, Cereser KM, Martins MR, Valvassori SS, Reus GZ, Quevedo J, Kapczinski $F$ (2006a) Effects of mood stabilizers on hippocampus BDNF levels in an animal model of mania. Life Sci 79(3):281-286

Frey BN, Valvassori SS, Reus GZ, Martins MR, Petronilho FC, Bardini K, Dal-Pizzol F, Kapczinski F, Quevedo J (2006b) Effects of lithium and valproate on amphetamineinduced oxidative stress generation in an animal model of mania. J Psychiatry Neurosci 31(5):326-332

Furukawa T, Ushizima I, Ono N (1975) Modifications by lithium of behavioral responses to methamphetamine and tetrabenazine. Psychopharmacologia 42(3):243-248

Goodwin FK, Jamison KR (2007) Manic Depressive Illness: Bipolar Disorders and Recurrent Depression, 2nd edition. Oxford University Press, New York, NY

Greil W, Ludwig-Mayerhofer W, Erazo N, Schochlin C, Schmidt S, Engel RR, Czernik A, Giedke H, Muller-Oerlinghausen B, Osterheider M, Rudolf GA, Sauer H, Tegeler J, Wetterling T (1997) Lithium versus carbamazepine in the maintenance treatment of bipolar disorders-a randomised study. J Affect Disord 43(2):151-161

Hamann S, Herman RA, Nolan CL, Wallen K (2004) Men and women differ in amygdala response to visual sexual stimuli. Nat Neurosci 7(4):411-416

Hartong EG, Moleman P, Hoogduin CA, Broekman TG, Nolen WA (2003) Prophylactic efficacy of lithium versus carbamazepine in treatment-naive bipolar patients. J Clin Psychiatry 64(2):144-151

Hernando V, Pastor J, Pedrosa M, Pena E, Sola RG (2008) Low-frequency bilateral hypothalamic stimulation for treatment of drug-resistant aggressiveness in a young man with mental retardation. Stereotact Funct Neurosurg 86(4):219-223

Hirschfeld RM, Weisler RH, Raines SR, Macfadden W (2006) Quetiapine in the treatment of anxiety in patients with bipolar I or II depression: a secondary analysis from a randomized, double-blind, placebo-controlled study. J Clin Psychiatry 67(3):355-362

Holschneider DP, Maarek JM (2004) Mapping brain function in freely moving subjects. Neurosci Biobehav Rev 28(5):449-461

Inskip HM, Harris EC, Barraclough B (1998) Lifetime risk of suicide for affective disorder, alcoholism and schizophrenia. Br J Psychiatry 172:35-37
Jacobs D, Silverstone T (1986) Dextroamphetamine-induced arousal in human subjects as a model for mania. Psychol Med 16(2):323-329

Judd LL, Akiskal HS, Schettler PJ, Endicott J, Maser J, Solomon DA, Leon AC, Rice JA, Keller MB (2002) The long-term natural history of the weekly symptomatic status of bipolar I disorder. Arch Gen Psychiatry 59(6):530-537

Kemp DE, Gao K, Ganocy SJ, Elhaj O, Bilali SR, Conroy C, Findling RL, Calabrese JR (2009) A 6-month, double-blind, maintenance trial of lithium monotherapy versus the combination of lithium and divalproex for rapid-cycling bipolar disorder and Co-occurring substance abuse or dependence. J Clin Psychiatry 70(1):113-121

Kruk MR (1991) Ethology and pharmacology of hypothalamic aggression in the rat. Neurosci Biobehav Rev 15(4):527-538

Kuhn J, Lenartz D, Mai JK, Huff W, Klosterkoetter J, Sturm V (2008) Disappearance of self-aggressive behavior in a brain-injured patient after deep brain stimulation of the hypothalamus: technical case report. Neurosurgery 62(5):E1182. discussion E1182

Kuncel AM, Grill WM (2004) Selection of stimulus parameters for deep brain stimulation. Clin Neurophysiol 115(11):2431-2441

Lacan G, De Salles AA, Gorgulho AA, Krahl SE, Frighetto L, Behnke EJ, Melega WP (2008) Modulation of food intake following deep brain stimulation of the ventromedial hypothalamus in the vervet monkey. Laboratory investigation. J Neurosurg 108(2):336-342

Laroche S, Davis S, Jay TM (2000) Plasticity at hippocampal to prefrontal cortex synapses: dual roles in working memory and consolidation. Hippocampus 10(4):438-446

Lejoyeux M, Ades J (1993) Evaluation of lithium treatment in alcoholism. Alcohol Alcohol 28(3):273-279

Marquis JP, Killcross S, Haddon JE (2007) Inactivation of the prelimbic, but not infralimbic, prefrontal cortex impairs the contextual control of response conflict in rats. Eur J Neurosci 25(2):559-566

Mayberg HS, Liotti M, Brannan SK, McGinnis S, Mahurin RK, Jerabek PA, Silva JA, Tekell JL, Martin CC, Lancaster JL, Fox PT (1999) Reciprocal limbic-cortical function and negative mood: converging PET findings in depression and normal sadness. Am J Psychiatry 156(5):675-682

Mayberg HS, Lozano AM, Voon V, McNeely HE, Seminowicz D, Hamani C, Schwalb JM, Kennedy SH (2005) Deep brain stimulation for treatment-resistant depression. Neuron 45(5):651-660

McElroy SL, Keck PE, Jr (2000) Pharmacologic agents for the treatment of acute bipolar mania. Biol Psychiatry 48(6):539-557

McElroy SL, Kotwal R, Keck PE, Jr, Akiskal HS (2005) Comorbidity of bipolar and eating disorders: distinct or related disorders with shared dysregulations? J Affect Disord 86(2-3):107-127

Mendlewicz J, Linkowski P (1987) Hypothalamic functions, sleep and circadian rhythms in affective disorders. Adv Biochem Psychopharmacol 43:221-236

Merikangas KR, Akiskal HS, Angst J, Greenberg PE, Hirschfeld RM, Petukhova M, Kessler RC (2007) Lifetime and 12-month prevalence of bipolar spectrum disorder in the National Comorbidity Survey replication. Arch Gen Psychiatry 64(5):543-552

Murray CJ, Lopez AD (1997) Alternative projections of mortality and disability by cause 1990-2020: global burden of disease study. Lancet 349(9064):1498-1504

Nolen WA, Weisler RH (2013) The association of the effect of lithium in the maintenance treatment of bipolar disorder with lithium plasma levels: a post hoc analysis of a double-blind study comparing switching to lithium or placebo in patients who responded to quetiapine (Trial 144). Bipolar Disord 15(1):100-109

Ongur D, Ferry AT, Price $J \mathrm{~L}$ (2003) Architectonic subdivision of the human orbital and medial prefrontal cortex. J Comp Neurol 460(3):425-449

Paxinos G, Watson C (1998) The Rat Brain in StereotaxicCoordinates, 4th edition. Academic Press, San Diego, CA

Pearlson GD, Barta PE, Powers RE, Menon RR, Richards SS, Aylward EH, Federman EB, Chase GA, Petty RG, Tien AY (1997) Ziskind-Somerfeld Research Award 1996. Medial and superior temporal gyral volumes and cerebral asymmetry in schizophrenia versus bipolar disorder. Biol Psychiatry 4(1):1-14

Perlis RH, Welge JA, Vornik LA, Hirschfeld RM, Keck PE, Jr (2006) Atypical antipsychotics in the treatment of mania: a meta-analysis of randomized, placebo-controlled trials. J Clin Psychiatry 67(4):509-516

Perry W, Minassian A, Paulus MP, Young JW, Kincaid MJ, Ferguson EJ, Henry BL, Zhuang X, Masten VL, Sharp RF, Geyer MA (2009) A reverse-translational study of dysfunctional exploration in psychiatric disorders: from mice to men. Arch Gen Psychiatry 66(10):1072-1080

Post RM, Weiss SR (1989) Sensitization, kindling, and anticonvulsants in mania. J Clin Psychiatry 50(Suppl):23-30. discussion 45-27 
Redoute J, Stoleru S, Gregoire MC, Costes N, Cinotti L, Lavenne F, Le Bars D, Forest MG, Pujol JF (2000) Brain processing of visual sexual stimuli in human males. Hum Brain Mapp 11(3):162-177

Roybal K, Theobold D, Graham A, DiNieri JA, Russo SJ, Krishnan V, Chakravarty S, Peevey J, Oehrlein N, Birnbaum S, Vitaterna MH, Orsulak P, Takahashi JS, Nestler EJ, Carlezon WA, Jr, McClung CA (2007) Mania-like behavior induced by disruption of CLOCK. Proc Natl Acad Sci U S A 104(15):6406-6411

Russo SJ, Nestler EJ (2013) The brain reward circuitry in mood disorders. Nat Rev Neurosci 14(9):609-625

Salloum IM, Cornelius JR, Daley DC, Kirisci L, Himmelhoch JM, Thase ME (2005) Efficacy of valproate maintenance in patients with bipolar disorder and alcoholism: a double-blind placebo-controlled study. Arch Gen Psychiatry 62(1):37-45

Scotti MA, Lee G, Stevenson SA, Ostromecki AM, Wied TJ, Kula DJ, Gessay GM, Gammie SC (2011) Behavioral and pharmacological assessment of a potential new mouse model for mania. Physiol Behav 103(3-4):376-383

Shaltiel G, Mark S, Kofman O, Belmaker RH, Agam G (2007) Effect of valproate derivatives on human brain myo-inositol-1-phosphate (MIP) synthase activity and amphetamine-induced rearing. Pharmacol Rep 59(4):402-407

Strakowski SM, Wilson DR, Tohen M, Woods BT, Douglass AW, Stoll AL (1993) Structural brain abnormalities in first-episode mania. Biol Psychiatry 33(8-9):602-609

Tondo L, Isacsson G, Baldessarini R (2003) Suicidal behaviour in bipolar disorder: risk and prevention. CNS Drugs 17(7):491-511

Vertes RP (2006) Interactions among the medial prefrontal cortex, hippocampus and midline thalamus in emotional and cognitive processing in the rat. Neuroscience 142(1):1-20

Whiting DM, Tomycz ND, Bailes J, de Jonge L, Lecoultre V, Wilent B, Alcindor D, Prostko ER, Cheng BC, Angle C, Cantella D, Whiting BB, Mizes JS, Finnis KW, Ravussin E, Oh MY (2013) Lateral hypothalamic area deep brain stimulation for refractory obesity: a pilot study with preliminary data on safety, body weight, and energy metabolism. J Neurosurg 119(1):56-63

Williams G, Bing C, Cai XJ, Harrold JA, King PJ, Liu XH (2001) The hypothalamus and the control of energy homeostasis: different circuits, different purposes. Physiol Behav 74(4-5):683-701

doi:10.1186/s40345-014-0007-8

Cite this article as: Abulseoud et al: Lateral hypothalamic kindling

induces manic-like behavior in rats: a novel animal model. International Journal of Bipolar Disorders 2014 2:7.

\section{Submit your manuscript to a SpringerOpen ${ }^{\circ}$ journal and benefit from:}

- Convenient online submission

- Rigorous peer review

- Immediate publication on acceptance

- Open access: articles freely available online

- High visibility within the field

- Retaining the copyright to your article

Submit your next manuscript at $\gg$ springeropen.com 